\title{
Surgical Management of a Type 11 Extracranial Internal Carotid Aneurysm near to the Skull Base
}

\author{
Miguel A. Mendez-Sosa, Emmanuel Contreras-Jimenez, Javier E. Anaya-Ayala, Montserrat \\ W. Miranda-Ramirez, Gabriel Lopez-Pena, Luis H. Arzola, Santiago Mier y Teran-Ellis, Hugo \\ Laparra-Escareno, and Carlos A. Hinojosa
}

Department of Surgery, Section of Vascular Surgery and Endovascular Therapy, Instituto Nacional de Ciencias Médicas y Nutrición Salvador Zubirán, México City, México

\begin{abstract}
True aneurysmal disease in the carotid arteries is very uncommon, but individuals with this pathology face the grave risk of thromboembolism, which may consequently lead to cerebrovascular accidents. Clinical knowledge remains relatively limited owing to its rarity. We present the case of a 41-year-old obese female with a type 11 right extracranial internal carotid artery aneurysm incidentally found during imaging work-up. She underwent open surgical reconstruction with an autologous interposition graft from the common carotid artery to the internal carotid artery at the base level of the skull. Her postoperative period was uneventful, and the patient was discharged on postoperative day five with aspirin. At 12 months of follow-up, the patient remained symptom-free without complications.
\end{abstract}

Key Words: Carotid artery diseases, Aneurysm, Internal carotid artery, Vascular grafting, Skull base
Received April 16, 2021

Revised July 6, 2021

Accepted July 13, 2021

Published on August 5, 2021

Copyright (c) 2021 The Korean Society for Vascular Surgery

This is an Open Access article distributed under the terms of the Creative Commons Attribution Non-Commercial License (http://creativecommons.org/licenses/by-nc/4.0) which permits unrestricted non-commercial use, distribution, and reproduction in any medium, provided the original work is properly cited.

Cite this article; Vasc Specialist Int 2021. https://doi.org/10.5758/vsi.210030

\section{INTRODUCTION}

Extracranial carotid artery aneurysms (ECAAs) can occur as a result of atherosclerotic degeneration, traumatic injury, dissection, local infection, or complications after a previous procedure; they account for $0.1 \%$ to $2 \%$ of all peripheral artery aneurysms [1]. ECAA is defined as a bulb dilation greater than 200\% of the diameter of the internal carotid artery (ICA) or greater than 150\% of the diameter of the common carotid artery (CCA), given that normal carotid bifurcation is typically $40 \%$ greater in diameter than that of the more distal ICA [2]. Surgical management of an ECAA was first reported by Sir Astley Cooper who performed ligation as treatment in 1808. Two main strategies have been described, namely conservative or aggressive interventions. Conservative strategies include antiplatelet, statin, and an- tihypertensive therapy. Conversely, more intensive methods such as open surgical and endovascular approaches are also currently available. The open procedure includes the following: 1) ligation, 2) resection with primary repair, 3) resection with graft interposition, and 4) resection with patch repair. For endovascular repair, covered stents, bare metal stents, and stents with coils in the aneurysm sac have been described [3].

Herein, we present the case of a 41-year-old female with a type 11 ECAA successfully treated with open surgery. We briefly discuss the clinical presentation, surgical planning, techniques, and outcomes. The case report was approved by the Institutional Review Board of the Instituto Nacional de Ciencias Medicas y Nutricion Salvador Zubiran (IRB no. SCl-3717-21-21-1). Informed consent was obtained from the patient prior to conducting our extensive analysis. 


\section{CASE}

A 41-year-old female was referred to our hospital upon the incidental finding of an ECAA. Magnetic resonance angiography revealed a right extracranial internal carotid artery aneurysm (ICAA) with a calcified plaque (Fig. 1). She
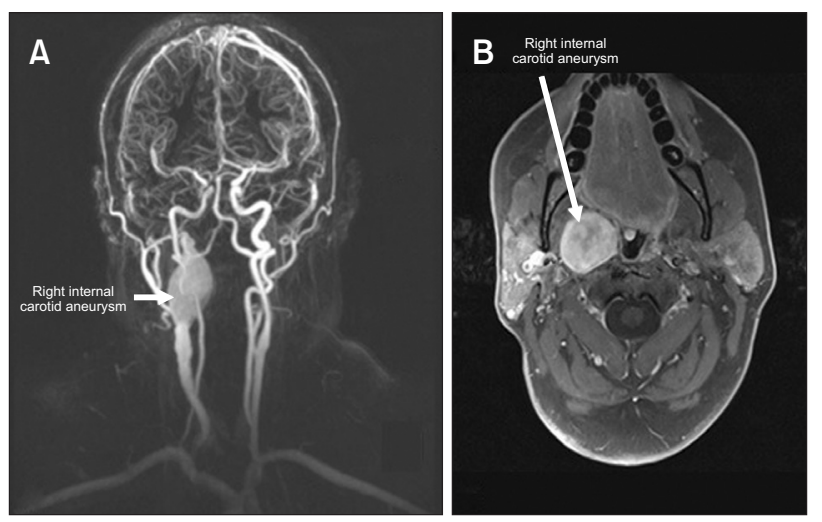

Fig. 1. Magnetic resonance angiography. (A) Common carotid artery has a proximal dilation before the bifurcation and the beginning of the aneurysm in the right internal carotid artery (arrow). The aneurysm has an extended dilation getting close to the base of the skull. (B) Axial view of the aneurysm at the most dilated portion (arrow). It revealed peripheral inflammatory tissue and a little deviation of the cervical portion of the trachea and the posterior portion of the tongue.
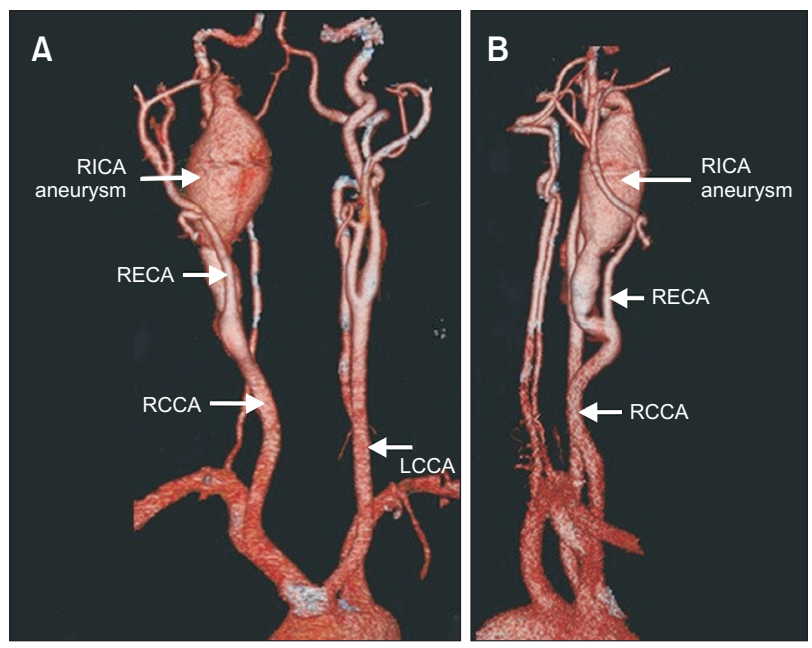

Fig. 2. Coronal projections of preprocedural computed tomography angiography. Anterior-posterior view (A) and right lateral view (B) showed a $2.6 \times 3.0 \mathrm{~cm}$ RICA aneurysm with turbulent flow and $3.5 \mathrm{~mm}$-sized calcified plaque. No thrombosis was documented. RICA, right internal carotid artery; RECA, right external carotid artery; RCCA, right common carotid artery; LCCA, left common carotid artery. was recently diagnosed with meningioma and had a history of hypertension, smoking, and obesity, with a body mass index of 37.6. The patient denied any neurological symptoms. Physical examination revealed a pulsatile mass on her right neck with a palpable thrill and systolic bruit. Computed tomography angiography (CTA) unveiled a tortuous extracranial ICA with a true aneurysm distal to the bifurcation measuring $30 \mathrm{~mm} \times 26 \mathrm{~mm}$ (Fig. 2). A full-body CTA showed no evidence of aneurysmal disease in the other arterial beds.

Open surgical repair was planned, and vein mapping of the lower limbs was performed with duplex ultrasonography (DUS) prior to surgery, demonstrating an adequate great saphenous vein (GSV) for the bypass conduit. After administering general endotracheal anesthesia, a longitudinal neck incision was made anterior to the sternocleidomastoid muscle, with a curve extending behind the ear lobe on the right side of the neck. The proximal and distal ICA was exposed through meticulous dissection, and proximal vascular control was performed on the CCA $3 \mathrm{~cm}$ proximal to the carotid bifurcation. Distal vascular control was performed $1 \mathrm{~cm}$ below the skull base using a Thompson retractor for better exposure and a Bard Brener Carotid Bypass Shunt (Bard Peripheral Vascular Inc., Tempe, AZ, USA). Brain perfusion was monitored by stump pressure. After retracting the parotid gland anteriorly, the hypoglossal and vagus nerves were identified and preserved, along with the digastric muscles. Mandibular subluxation and resection of the styloid process were deemed unnecessary. The aneurysm was successfully resected, and ICA flow was reconstructed with a GSV graft by end-to-end anastomoses using the parachute technique (Fig. 3).

The pathology report confirmed chronic inflammation,

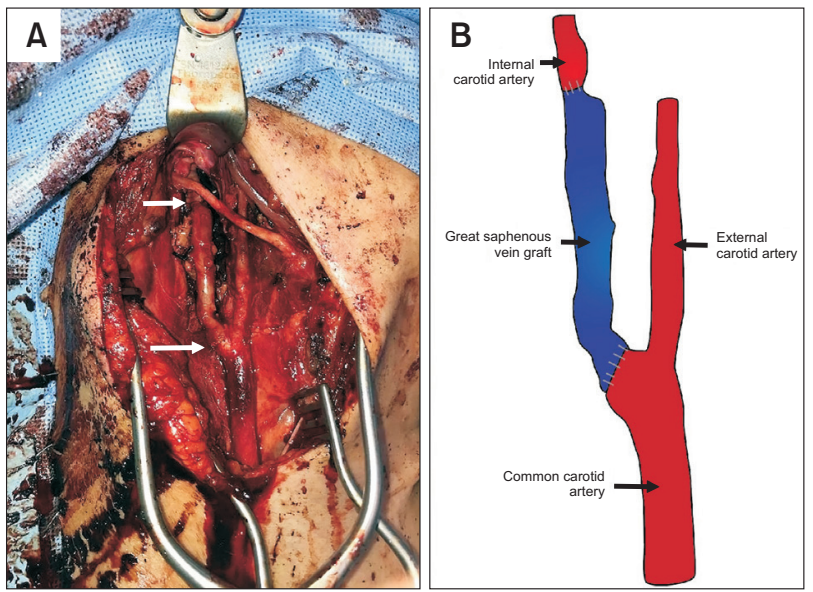

Fig. 3. (A) Intraoperative photograph shows carotid-carotid interposition graft (arrows). (B) Schematic drawing of the surgical reconstruction. 
atheromatous plaque, and mural thrombi inside the sac. Antiplatelet therapy with aspirin $100 \mathrm{mg} /$ day was administered. She was discharged with no neurological complications on the fifth postoperative day. Similarly, DUS on the 15th postoperative day revealed good flow in the vein graft. After 12 months, the patient remained asymptomatic, without neurological deficits.

\section{DISCUSSION}

The incidence of true aneurysms involving the extracranial ICA accounts for less than $1 \%$ of cases $[2,4]$, and clinical findings may vary according to their location, size, and etiology. The most common symptoms are pulsatile mass, local pain, and dysphagia, but more important manifestations that heighten suspicion of this pathology are neurological symptoms. Amaurosis fugax is the most commonly reported neurological complication, but other cases also involve transient ischemic attack, stroke, Horner's syndrome, and cranial nerve dysfunction (involving the vagus or recurrent laryngeal nerve, facial nerve, trigeminal or abducens nerve, depending on the extent of the mass) [13]. In this case, the patient presented with a pulsatile mass. However, she neither exhibited neurological deficits nor manifest local pain or dysphagia.

The Attigah classification distinguishes ECAAs according to their location and extension (Fig. 4). Type 1 is an aneurysm of the ICA distal to the carotid bifurcation; Type 11 , an aneurysm of the ICA; Type 111, a lesion at the carotid bifurcation; Type IV, an aneurysm involving both the ICA and CCA; and Type V, an aneurysmal disease affecting the CCA. Type 1 was most prevalent (39\%), followed by Type 111 (31.2\%). In this case, our patient presented with a Type 11 extracranial ICA aneurysm, which represented 12.5\% of all described types [5].

Until the 1950s, surgical treatment mainly utilized carotid artery ligation, an aggressive method linked to a mortality and major stroke rate of $20 \%$ to $40 \%$ [6]. Although this technique may prevent the expansion and embolic complications of the aneurysm, ligation should only be considered when reconstruction is impossible to carry out in carefully selected patients. Surgical treatment requires an approach meticulously based on the etiology, size, and location of the aneurysm, associated factors, and existing comorbidities $[7,8]$. Given the rapid development of endovascular technology, it has become a preferred option among endovascular surgeons as a vital method for treating CAA [9,10]. The 30day outcomes of endovascular procedures are reported to be better than those of open surgical procedures [10]. The durability and thrombosis rates, which were 93.2\% with stent grafts and 97\% with bare metal stents, along with sac thrombosis rates of 93\% and 70.6\%, respectively, were comparatively lower than those of conventional repair. In addition, a stent thrombosis rate of $6.5 \%$ and stroke rate of $2.5 \%$ were also not insignificant $[9,11]$.

Ultimately, both open and endovascular approaches should be patient-specific and carefully selected. Moreover, chosen techniques should depend on anatomic suitability for the most optimal outcomes. For favorable durability, we elected to conduct open repair with an interposition graft in this otherwise young and healthy patient. We performed an open surgical procedure with a carotid-carotid bypass. The circle of Willis was intact in this patient. Although the aneurysm extended to a high level, distal control was still obtained without issue.

In conclusion, this case illustrates the successful surgi-

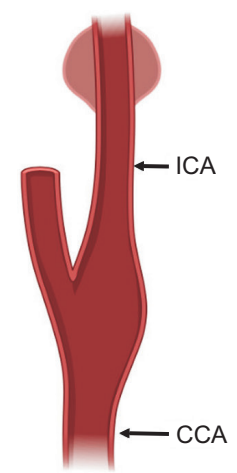

Type I

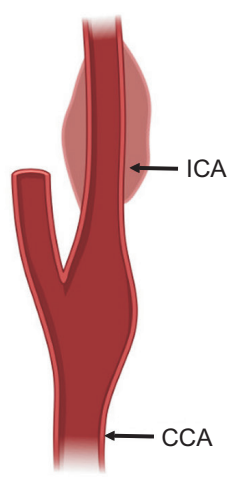

Type II

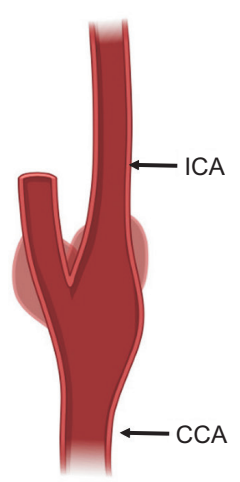

Type III

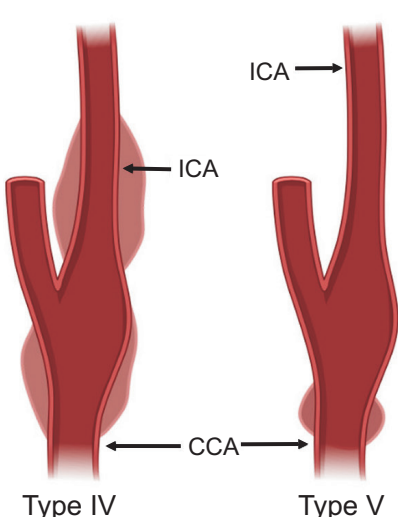

Type IV
Type V

Fig. 4. Classification for extracranial carotid artery aneurysms according to Attigah, based on the anatomy of the aneurysm. Type I, Aneurysms of the internal carotid artery distal to the carotid bifurcation; Type II, Aneurysm of the internal carotid artery; Type III, Aneurysm of the carotid bifurcation; Type IV, Aneurysm of the internal carotid artery and the common carotid artery; Type $\mathrm{V}$, Aneurysm of the common carotid artery. ICA, internal carotid artery; CCA, common carotid artery. 
cal repair of a type 11 extracranial ICAA after 12 months of follow-up.

\section{CONFLICTS OF INTEREST}

The authors have nothing to disclose.

\section{ORCID}

Miguel A. Mendez-Sosa

https://orcid.org/0000-0002-0591-6523

Emmanuel Contreras-Jimenez

https://orcid.org/0000-0002-2733-6255

Javier E. Anaya-Ayala

https://orcid.org/0000-0003-0936-3310

Montserrat W. Miranda-Ramirez

https://orcid.org/0000-0001-9179-8705

Gabriel Lopez-Pena

https://orcid.org/0000-0001-8839-0899
Luis H. Arzola

https://orcid.org/0000-0001-8876-5937

Santiago Mier y Teran-Ellis

https://orcid.org/0000-0003-4663-5346

Hugo Laparra-Escareno

https://orcid.org/0000-0002-2233-6037

Carlos A. Hinojosa

https://orcid.org/0000-0002-9664-8703

\section{AUTHOR CONTRIBUTIONS}

Concept and design: CAH. Analysis and interpretation: JEAA, MWMR. Data collection: MAMS. Writing the article: MAMS, ECJ, JEAA, MWMR, GLP, LHA, SMTE. Critical revision of the article: JEAA, HLE, CAH. Final approval of the article: all authors. Statistical analysis: none. Obtained funding: none. Overall responsibility: CAH.

\section{REFERENCES}

1) Kraemer CJK, Zhou W. Carotid aneurysm review. Int J Angiol 2019;28:1719.

2) de Jong KP, Zondervan PE, van Urk H. Extracranial carotid artery aneurysms. Eur J Vasc Surg 1989;3:557-562.

3) de Borst GJ, van Laarhoven CJH, Pourier VEC. Treatment of extracranial carotid artery aneurysms: what is known and what is unknown? EJVES Short Rep 2017;38:23.

4) Chen Z, Chen L, Zhang J, Chen Y, Liu C, Diao Y, et al. Management of extracranial carotid artery aneurysms: a 6-year case series. Med Sci Monit 2019;25:4933-4940.

5) Attigah N, Külkens S, Zausig N, Hansmann J, Ringleb P, Hakimi M, et al. Surgical therapy of extracranial ca- rotid artery aneurysms: long-term results over a 24-year period. Eur J Vasc Endovasc Surg 2009;37:127-133.

6) Painter TA, Hertzer NR, Beven EG, O'Hara PJ. Extracranial carotid aneurysms: report of six cases and review of the literature. J Vasc Surg 1985;2:312-318.

7) Xue S, Tang X, Zhao G, Tang H, Shen $Y$, Yang EY, et al. Contemporary outcomes of open and endovascular intervention for extracranial carotid artery aneurysms: a single centre experience. Eur J Vasc Endovasc Surg 2020;60:347-354.

8) Welleweerd JC, den Ruijter HM, Nelissen BG, Bots ML, Kappelle LJ, Rinkel GJ, et al. Management of extracranial carotid artery aneurysm. Eur J Vasc
Endovasc Surg 2015;50:141-147.

9) Li Z, Chang G, Yao C, Guo L, Liu Y, Wang $\mathrm{M}$, et al. Endovascular stenting of extracranial carotid artery aneurysm: a systematic review. Eur J Vasc Endovasc Surg 2011;42:419-426.

10) Giannopoulos S, Trinidad E, Aronow H, Soukas P, Armstrong EJ. Endovascular repair of extracranial carotid artery aneurysms: a systematic review. Vasc Endovascular Surg 2020;54:254-263.

11) Illuminati G, Pizzardi G, Pasqua R, Nardi P, Calio' FG, Ricco JB. Longterm results of polytetrafluoroethylene versus saphenous vein repair of degenerative carotid artery aneurysm. J Vasc Surg 2020;72:1413-1420. 